\title{
ECO-TECHNOLOGIES FOR OBTAINING AMINOACID BASED SURFACTANTS
}

\author{
Irina Elena Chican ${ }^{1}$, Dana Simona Varasteanu ${ }^{1}$, Loti Cornelia Oproiu¹, Sanda Maria \\ Doncea $^{1}$
}

${ }^{1}$ National Research\&Development Institute for Chemistry\&Petrochemistry - ICECHIM, Splaiul Independentei 202, 060021, Bucharest, Romania, organica@icechim.ro

\begin{abstract}
Two surfactants with one hydrophilic head group (lauroyl hydroxyproline and palmitoyl hydroxyproline) and a bolaamphiphilic surfactant, with two hydrophilic head groups $(1,12$ dodecanedioyl diglycylglycine) were synthesized using a method with reduced environmental impact. The high conversions in useful product were sustained by FTIR analysis. It was evaluated the surface activity of aqueous solutions of surfactants' sodium salts and it was demonstrated a significant reduction in the surface tension compared to distilled water. Synthesized surfactants can be a viable alternative for the petrochemical products.
\end{abstract}

Keywords: Bio-based surfactants, Amino acids, Eco-technologies

\section{Introduction}

Surfactants can affect the environment and human health in the synthesis steps (staff exposure to toxic products, emissions to air, water, soil), stage of use (consumer exposure through skin contact, ingestion or accidental inhalation), and the final stage of the surfactant's life cycle, namely environmental release. As a result, in recent decades the European legislation on environmental protection and human health has been subject to increasingly stringent regulations. Along with specific legislative regulations (Regulation 648/2004 / EC), surfactants and their raw materials are also subject to regulations on substances and chemicals (REACH), which creates a market for "green chemistry". The principles of "green chemistry" refer mainly to the design of chemical processes which generate a minimum quantity of wastes, the use of less toxic or non-toxic substances to humans and the environment, the use of renewable raw materials, the use of safer solvents and mild reaction conditions.

A natural surfactant, in strict terms, is obtained from natural sources, by methods of separation such as extraction, precipitation, without being modified by chemical synthesis [1-5]. There are few natural surfactants that meet these conditions and the cost of production of these natural surfactants is much higher than equivalent surfactants produce by chemical synthesis, due to laborious separation processes and the reduced amount of substance in the natural product. The alternative is represented by surfactants obtained by chemical synthesis from renewable raw materials, animal or vegetable.

Due to structural and functional similarity with natural systems, the variety and availability of raw materials, amino acid based surfactants are ideal candidates for the development of non-toxic and biodegradable products. Amino acid-based surfactants known continuous progress in areas such as pharmaceuticals, cosmetics and detergents, due to lack of toxicity, gentle action on the skin, good surface activity, high degree of biodegradability. The most important class of amino acid based surfactants 
is represented by $\mathrm{N}$-acyl derivatives (acyl amino acids), comprising anionic, cationic, amphoteric or non-ionic surfactants, depending on the ionic nature of the amino acid. Synthesis methods include enzymatic [6-8] and chemo-enzymatic [9] processes, but mainly chemical methods due to relatively low production costs [10-12].

In this work we have focused on synthesis of surfactants based on hydroxyproline and glygylglycine amino acids, through processes with low environmental impact. We have prepared and characterized two surfactants with one hydrophilic head-group (lauroyl hydroxyproline, palmitoyl hydroxyproline) and one surfactant with two hydrophilic head-groups (1,12-dodecanedioyl diglycylglycine). The structures of synthesized surfactants were confirmed by FT-IR and the surface properties of surfactants were determined by means of surface tension measurements.

\section{Experimental}

\subsection{Synthesis of lauroyl hydroxyproline, palmitoyl hydroxyproline and 1,12- dodecanedioyl diglycylglycine}

Raw materials used were: 4-hydroxyproline (Hyp) - molecular weight $131.13 \mathrm{~g} / \mathrm{mol}$, min. 99\% purity; Glycylglycine (GG) - 132.12 molecular weight, min. 99\% purity; Lauroyl chloride (CL) - molecular weight $218.77 \mathrm{~g} / \mathrm{mol}$, density $0.922 \mathrm{~g} / \mathrm{cm}^{3}, \min .98 \%$ purity; Palmitoyl chloride (CP) - molecular weight $274.88 \mathrm{~g} / \mathrm{mol}$, density $0.906 \mathrm{~g} / \mathrm{cm}^{3}$, min. 98\% purity; Dodecandioyl dichloride (DDD): molecular weight $267.19 \mathrm{~g} / \mathrm{mol}$, density $1.069 \mathrm{~g} / \mathrm{cm}^{3}$, min. $98 \%$ purity.

The surfactants were synthesized by using the Schotten-Baumann method. For lauroyl hydroxyproline and palmitoyl hydroxyproline the reaction is presented in figure 1.

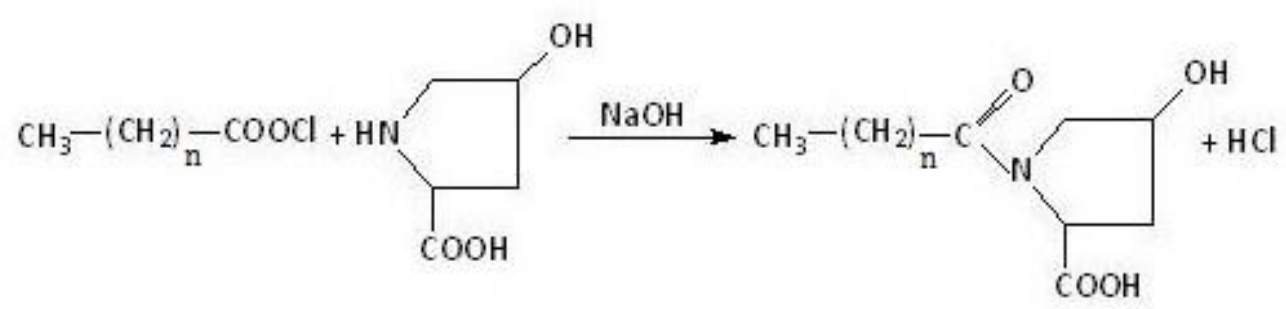

Figure 1 - The synthesis reaction of acyl hydroxyproline surfactants $(n=10,14)$

In a reaction vessel of $250 \mathrm{~mL}$ capacity, equipped with dropping funnel, thermometer and electric stirrer 0,1 mol hydroxiproline was introduced and allowed to dissolve in a mixture of acetone/ distilled water. The $\mathrm{pH}$ was adjusted to 10 using $25 \% \mathrm{NaOH}$ solution. To this solution was added dropwise 0,1 mol lauroil chloride or palmitoyl chloride. During acid chloride addition the temperature was kept constant at $10^{\circ} \mathrm{C}$ (cryostat), and if necessary a solution of $\mathrm{NaOH}$ was added to maintain a constant $\mathrm{pH}$ of 9-10. After the entire amount of acid chloride was added the temperature was raised to $30-50^{\circ} \mathrm{C}$ and the reaction was allowed to complete. Thereafter the solution was cooled and the $\mathrm{pH}$ is adjusted to 1.5 by adding $35 \%$ hydrochloric acid. The resulted precipitate was filtered under vacuum and washed on the filter with distilled water to remove traces of unreacted amino acid. The filtrate is then oven dried at a temperature less than $50^{\circ} \mathrm{C}$, in order to avoid the product degradation. The acylation rate is calculated from the initial content of aminic nitrogen and final content of aminic nitrogen in the reaction mixture.

For 1,12-dodecanedioyl diglycylglycine the reaction is presented in figure 2 . 


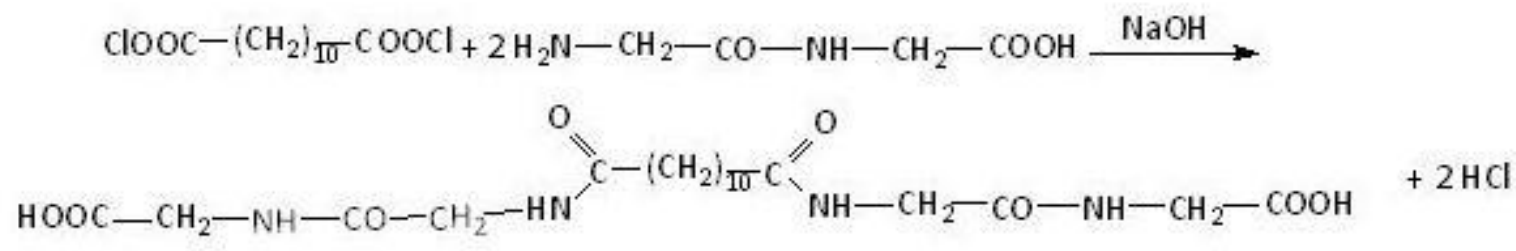

Figure 2 - The synthesis reaction of 1,12-dodecanedioyl diglycylglycine

The synthesis proceeds in the same way as for lauroyl hydroxyproline and palmitoyl hydroxyproline, using a molar ratio glycylglycine:dodecandioil dichloride of $2: 1$.

\subsection{FTIR spectroscopy}

For structural characterization of synthesized products Fourier transform infrared spectroscopy (FTIR) spectra of raw materials hydroxyproline, glycylglycine, lauroyl chloride, palmitoyl chloride, dedecanedioyl dichloride and surfactants lauroyl hydroxyproline, palmitoyl hydroxyproline and 1,12-dodecanedioyl diglycylglycine were registered with a Spectrum GX, Perkin Elmer instrument, by KBr pellet procedure.

\subsection{Surface tension}

The surface tension of aqueous solutions of surfactants was measured with a KSV Sigma 700 automated tensiometer. The measurements were performed using the Du Nouy ring technique. The solutions of amino acid-based surfactants (lauroyl hydroxyproline, palmitoyl hydroxyproline and 1,12-dodecanedioyl diglycylglycine) were neutralized at $\mathrm{pH} 8$ with a $25 \% \mathrm{NaOH}$ solution, in order to solubilize the surfactant in aqueous solution, ensuring the formation of the active part of the molecule, namely the anion $\mathrm{R}^{-\mathrm{COO}}$ and avoiding the precipitation of the insoluble acidic form of the surfactant.

\section{Results and Discussion}

The syntheses of amino acid based surfactants were performed according to the principles of green chemistry: use of renewable raw materials (amino acids), the use of less toxic solvents and mild reaction conditions, increased efficiency energy (low reaction temperature). The synthesis reaction selected for this type of surfactants is Schotten-Baumann reaction, in alkaline catalysis, using an acid chloride, known to have a high reactivity. In order to prevent as far as possible side reactions, the temperature should be kept low, especially during the addition of acid chloride $\left(10^{\circ} \mathrm{C}\right.$, assured with the means of a cryostat), and the acid chloride is added slowly, in small quantities. At the same time the alkaline medium should be kept during the reaction, to drive the equilibrium toward the formation of amides.

The acylation rate (AR), the yield and the specific reaction conditions for the synthesis of synthesized surfactants are given in Table 1. 
Table 1 - Reaction conditions for the synthesis of hydroxyproline- and glycylglycine- based surfactants

\begin{tabular}{|c|c|c|c|c|c|c|c|}
\hline Product & $\begin{array}{c}\text { Molar ratio } \\
\text { amino acid: } \\
\text { acid chloride }\end{array}$ & $\begin{array}{c}\text { Reaction } \\
\text { medium }\end{array}$ & $\begin{array}{c}\text { Adding } \\
\text { temp. acid } \\
\text { chloride, }{ }^{0} \text { C }\end{array}$ & $\begin{array}{c}\text { Post } \\
\text { reaction } \\
\text { temp., }{ }^{0} \text { C }\end{array}$ & $\begin{array}{c}\text { Post } \\
\text { reaction } \\
\text { time,min. }\end{array}$ & $\begin{array}{c}\text { AR, } \\
\%\end{array}$ & $\mathbf{n , ~ \%}$ \\
\hline $\begin{array}{c}\text { Lauroyl } \\
\text { hydroxyproline }\end{array}$ & $1: 1$ & $\begin{array}{c}\text { Water/ } \\
\text { acetone }\end{array}$ & 10 & 35 & 120 & 99.63 & 93.7 \\
\hline $\begin{array}{c}\text { Palmitoyl } \\
\text { hydroxyproline }\end{array}$ & $1: 1$ & $\begin{array}{c}\text { Water/ } \\
\text { acetone }\end{array}$ & 10 & 35 & 120 & 97 & 96.59 \\
\hline $\begin{array}{c}1,12- \\
\text { dodecanedioyl } \\
\text { diglycylglycine }\end{array}$ & $2: 1$ & $\begin{array}{c}\text { Water/ } \\
\text { acetone }\end{array}$ & 30 & 50 & 120 & 89 & 56.76 \\
\hline
\end{tabular}

Lauroyl hydroxyproline was characterized by FTIR spectroscopy, as presented in figure 3. The spectra of raw materials hydroxyproline and lauroyl chloride were also registered.

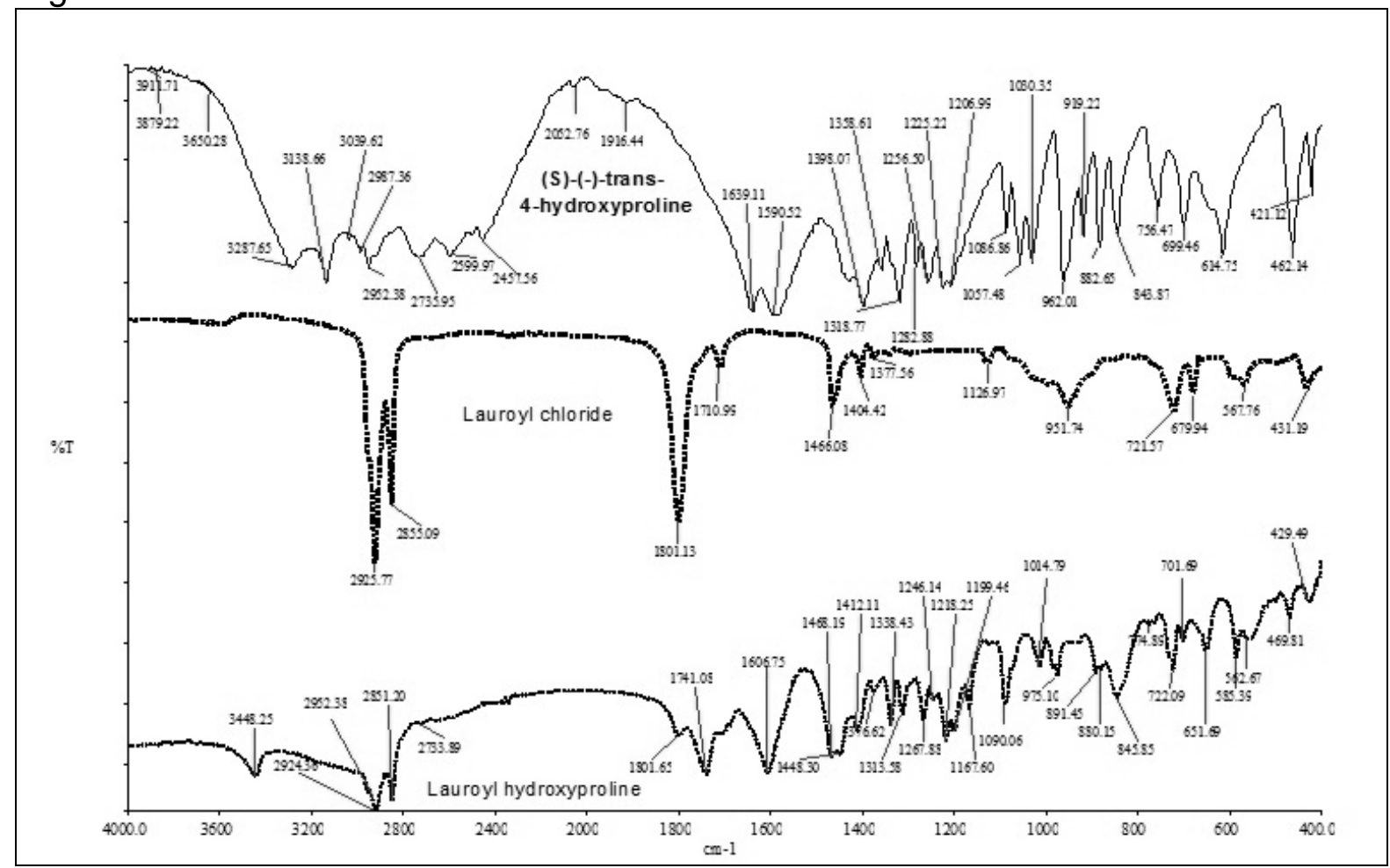

Figure 3 - FTIR spectra of lauroyl hydroxyproline and raw materials

The FTIR spectrum of 4-hydroxyproline presents characteristic absorption bands: 3650 $\mathrm{cm}^{-1}$, associated to $-\mathrm{OH}$ group, $3288 \mathrm{~cm}^{-1}, 3139 \mathrm{~cm}^{-1}, 2736 \mathrm{~cm}^{-1}$ and $1591 \mathrm{~cm}^{-1}$ corresponding to $\mathrm{NH}$ group. Carbonyl absorption bands appear at $1639 \mathrm{~cm}^{-1}, 1397 \mathrm{~cm}^{-}$ 1 and $1359 \mathrm{~cm}^{-1}$. At $1283 \mathrm{~cm}^{-1}$ the band is assigned to $\mathrm{CH}$ bond. The ring torsions appear in low frequency region: $1087 \mathrm{~cm}^{-1}, 1030 \mathrm{~cm}^{-1}, 844 \mathrm{~cm}^{-1}, 615 \mathrm{~cm}^{-1}$ for C-C and $962 \mathrm{~cm}^{-1}, 883 \mathrm{~cm}^{-1}$ for $\mathrm{C}-\mathrm{N}$ bond. The deformation of $-\mathrm{COOH}$ group is obtained at 699 $\mathrm{cm}^{-1}, 462 \mathrm{~cm}^{-1}[13]$.

Lauroyl chloride presents the characteristic absorption bands: $\mathrm{CH}_{2}$ group stretching vibration appears at $2926 \mathrm{~cm}^{-1}$ and $2855 \mathrm{~cm}^{-1}$. $\mathrm{CH}_{2}$ deformation vibration appears as a double band at $1466 \mathrm{~cm}^{-1}$ and $1404 \mathrm{~cm}^{-1}$. (-(CH2) $\left.\mathrm{n}^{-}, \mathrm{n}>3\right)$ appears at $722 \mathrm{~cm}^{-1}$, corresponding to long chain hydrocarbon. $\mathrm{C}=\mathrm{O}$ bond characteristic band appears at 
much higher frequency than in the case of anhydrides, esters or amides of carboxylic acids: $1801 \mathrm{~cm}^{-1}, 1711 \mathrm{~cm}^{-1}$.

In the FTIR spectrum of lauroyl hydroxyproline it can be noted that $\mathrm{C}=\mathrm{O}$ bands have much lower intensity than in lauroyl chloride, indicating a high acylation rate of amino acid. The absorption bands of reactants appear in final product with small shifts. Additionally, new bands attributed to amidic bond appear: $1639 \mathrm{~cm}^{-1}$ (Amide band I: stretching vibrations of the $\mathrm{C}=\mathrm{O}$ bond of the amide), $1448 \mathrm{~cm}^{-1}$ (Amide band II: bending vibrations of the $\mathrm{N}-\mathrm{H}$ bond). A small amount of hydroxyproline was esterified, the $\mathrm{C}$ $\mathrm{O}-\mathrm{C}$ appears at $1168 \mathrm{~cm}^{-1}$.

The spectra of palmitoyl hydroxyproline and of raw materials hydroxyproline and palmitoyl chloride are presented in figure 4.

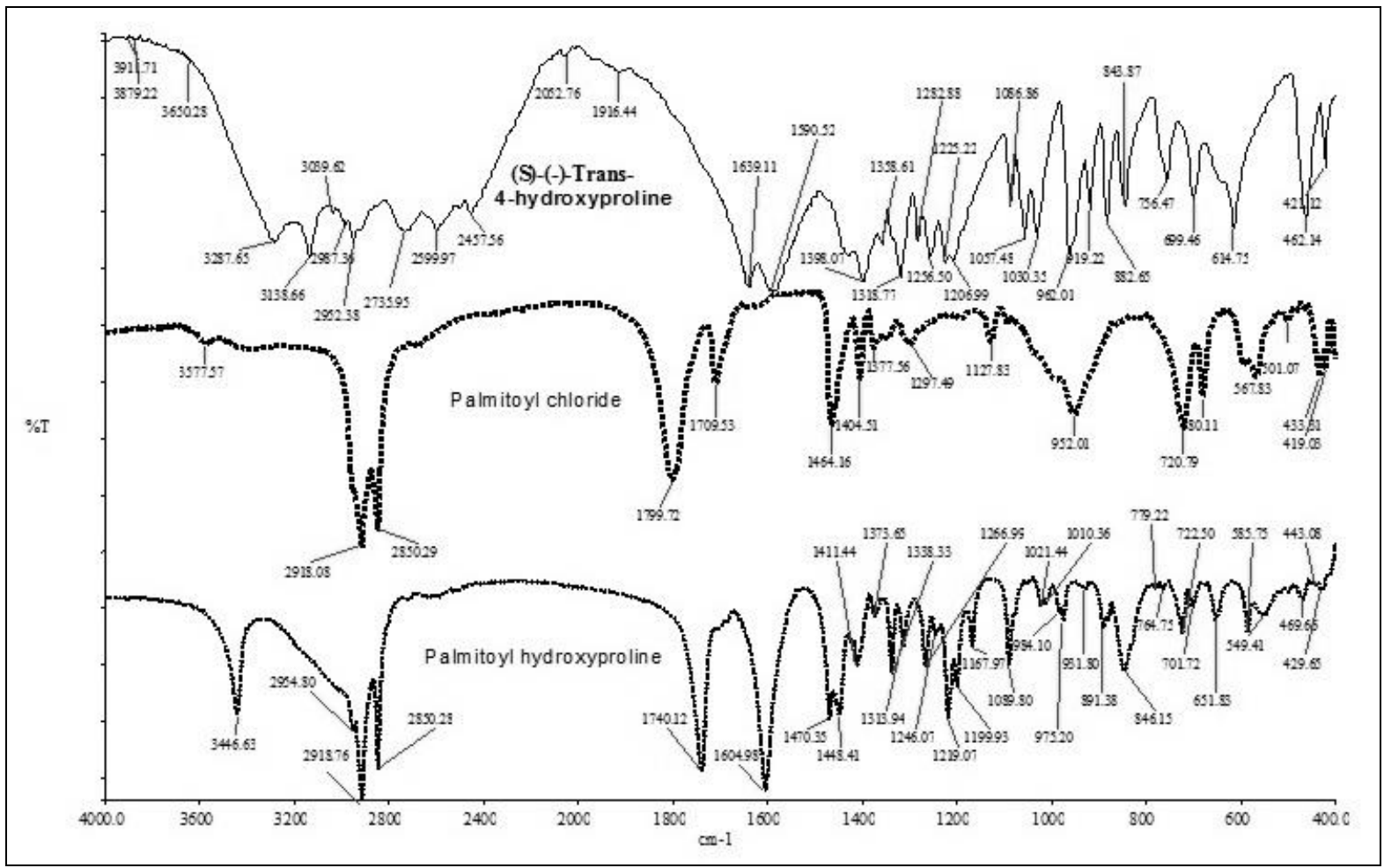

Figure 4 - FTIR spectra of palmitoyl hydroxyproline and raw materials

In the spectrum of palmitoyl hydroxyproline it can be noted that there is no $\mathrm{C}=\mathrm{O}$ band at $1800 \mathrm{~cm}^{-1}$, as in palmitoyl chloride spectrum, indicating the acylation of amino acid. The absorption bands of reactants appear in final product with small shifts. Additionally, new bands attributed to amidic bond appear: $1605 \mathrm{~cm}^{-1}$ (Amide band I: stretching vibrations of the $\mathrm{C}=\mathrm{O}$ bond of the amide), $1470 \mathrm{~cm}^{-1}$ (Amide band II: bending vibrations of the $\mathrm{N}-\mathrm{H}$ bond). A small amount of hydroxyproline was esterified, the $\mathrm{C}-\mathrm{O}-\mathrm{C}$ appears at $1168 \mathrm{~cm}^{-1}$.

The spectra of 1,12-dodecanedioyl diglycylglycine and of raw materials glycylglycine and 1,12-dodecanedioyl dichloride are presented in figure 5. 


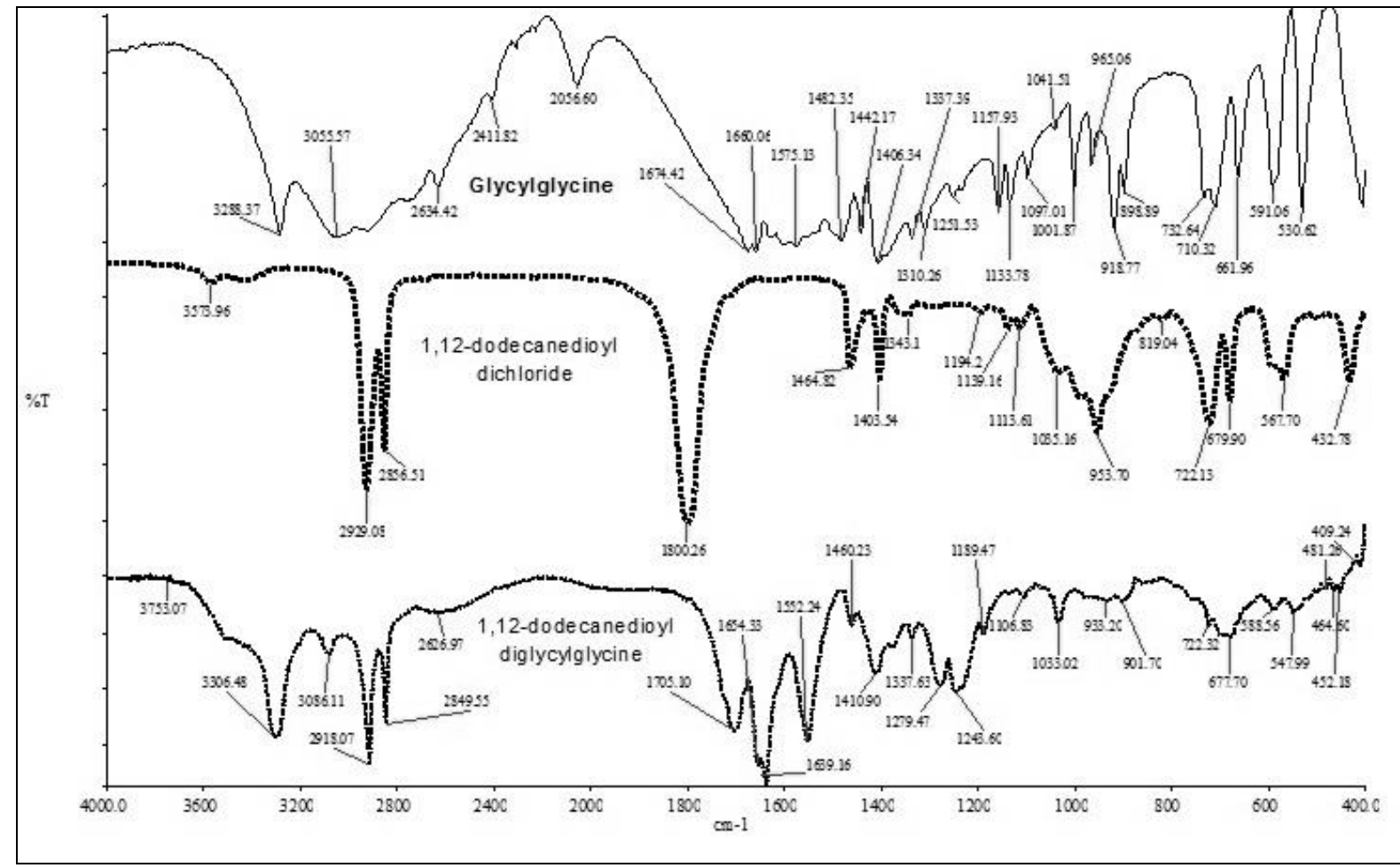

Figure 5 - FTIR spectra of 1,12-dodecanedioyl diglycylglycine and raw materials

The FTIR spectrum of glycylglycine presents characteristic absorption bands of amides: the amide I appears as doublet bands at $1674 \mathrm{~cm}^{-1}$ and $1660 \mathrm{~cm}^{-1}$ and amide II at $1482 \mathrm{~cm}^{-1}$ and $1442 \mathrm{~cm}^{-1}$ [14].

Dodecandioyl dichloride presents characteristic absorption bands in FTIR spectrum: $\mathrm{CH}_{2}$ group stretching vibration at $2929 \mathrm{~cm}^{-1}$ and $2857 \mathrm{~cm}^{-1}, \mathrm{CH}_{2}$ vibration deformation at $1465 \mathrm{~cm}^{-1}$ and $1404 \mathrm{~cm}^{-1},\left(-(\mathrm{CH} 2)_{n-}^{-}, n>3\right)$ at $722 \mathrm{~cm}^{-1}$, corresponding to long chain hydrocarbon. Dodecanedioyl dichloride shows a strong $\mathrm{C}=\mathrm{O}$ band at $1800 \mathrm{~cm}^{-1}$, also a C-Cl stretch at $680 \mathrm{~cm}^{-1}$.

The esterification reaction is proved by the absorption bands found in 1,12dodecanedioyl diglycylglycine spectrum and also in reactants spectra, with small shifts, but especially by the absorption bands for amide I at $1654 \mathrm{~cm}^{-1}$ and $1639 \mathrm{~cm}^{-1}$ and amide II at $1460 \mathrm{~cm}^{-1}$ and $1410 \mathrm{~cm}^{-1}$. A small amount of hydroxyproline was esterified, the C-O-C appears at $1189 \mathrm{~cm}^{-1}$.

Evaluation of the surface activity of the surfactants was carried out by determining the surface tension of $1 \%$ aqueous solutions of neutralized surfactants. Measurements were carried out with a KSV automatic tensiometer, model Sigma 700. The table 2 shows the values of surface tension for the products synthesized and neutralized ( $1 \%$ aq.), compared to distilled water.

Table 2 - Surface tension of amino acid based surfactants

( $1 \%$ aqueous solution) vs. surface tension of water

\begin{tabular}{|l|c|}
\hline Water & Surface tension (mN/m) \\
\hline $\begin{array}{l}\text { Lauroyl hydroxyproline sodium salt } \\
\text { (1\% aqueous solution) }\end{array}$ & 41.59 \\
\hline $\begin{array}{l}\text { Palmitoyl hydroxyproline sodium } \\
\text { salt (1\% aqueous solution) }\end{array}$ & 40.99 \\
\hline $\begin{array}{l}1,12-\text { dodecanedioyl diglycylglycine } \\
\text { sodium salt (1\% aqueous solution) }\end{array}$ & 51.02 \\
\hline
\end{tabular}


The analysis of experimental data from table 2 led to the conclusion that the aqueous solutions of the sodium salts of lauroyl hydroxyproline, palmitoyl hydroxyproline and 1,12-dodecanedioyl diglycylglycine significantly reduce the surface tension of distilled water.

\section{Conclusions}

The syntheses of amino acid based surfactants were performed by methods with reduced environmental impact. Acylation reactions were performed in alkaline catalysis, using a water/acetone medium, at temperatures of $\max .50^{\circ} \mathrm{C}$, in accordance with the principles of green chemistry: the use of renewable raw materials (amino acids), the use of safe solvents and reaction conditions (low toxicity solvents), increased energy efficiency (reaction temperatures up to $50^{\circ} \mathrm{C}$ ). High acylation rates and reaction yields were obtained especially for lauroyl hydroxyproline and palmitoyl hydroxyproline. Acylation reaction was confirmed by FTIR analysis. The determination of surface active properties of amino acid based surfactants showed a high efficiency in reducing the surface tension of distilled water.

\section{Acknowledgements}

This work was financially supported by National Authority for Scientific Research and Innovation, in the frame of Nucleu Programme-Project PN 16.31.02.03.

\section{References}

1. Chen, Y. F., Yang, C. H., Chang, M. S., Ciou, Y. P., \& Huang, Y. C. (2010) Foam properties and detergent abilities of the saponins from Camellia oleifera, International Journal of Molecular Sciences, 11(11), 4417-4425

2. Jacques A., Pirotton P., 1989, Stable aqueous fabric softening compositions based on lecithin, saponin and sorbic acid and methods for making and using same, US Patent 4816170 3. Tamura Y., Miyakoshi M., Yamamoto M., (2012) Application of Saponin-Containing Plants in Foods and Cosmetics, Alternative Medicine, available online on http://www.intechopen.com/books/alternative-medicine/application-of-saponin-containingplants-in-foods-and-cosmetics, 2012.

4. Kensil C. A., Marciani D.J., Soltysik S., 1999, Methods for enhancing drug delivery with modified saponins, Cambridge Biotech Corporation, EP 0658111 B1

5. Nguyen T.T., Sabatini D.A., (2011) Characterization and Emulsification Properties of Rhamnolipid and Sophorolipid Biosurfactants and Their Applications, International Journal of Molecular Sciences, 12, 1232-1244

6. Morán M., Pinazo A., Pérez L., Clapés P., Pons R., Infante M.R (2004) Enzymatic synthesis and physicochemical characterization of glycero arginine-based surfactants, Comptes Rendus Chimie, 7, 169-176

7. Wada E., Handa M., Imamura K., Sakiyama T., Adachi S., Matsuno R., Nakanishi K., (2002) Enzymatic synthesis of $\mathrm{N}$-acyl-L-amino acids in a glycerol-water system using acylase I from pig kidney, Journal of the American Oil Chemists' Society, 79(1), 41-46

8. Clapés P., Infante M.R. (2002) Amino Acid-based Surfactants: Enzymatic Synthesis, Properties and Potential Applications, Biocatalysis Biotransformation, 20(4), 215-233

9. Valivety R., Jauregi P., Gill I., Vulfson E. (1997) Chemo-enzymatic synthesis of amino acidbased surfactants, Journal of the American Oil Chemists' Society, 7, 879-886

10 Infante. M.R., Pérez L., Pinazo A., Clapés P., Morán M. C. , Angelet M., García M. T., Vinardell M. P. (2004) Amino acid-based surfactants, Comptes Rendus Chimie, 7, 583-592 11. Penney C. L., Shah P., Landi S. (1985) A Simple Method for the Synthesis of Long-chain Alkyl Esters of Amino Acids, Journal of Organic Chemistry, 50, 1457-1459 
12. Claffey D. J., Meyer J. D., Beauvais R., Brandt T., Shefter E., Kroll D. J., Ruth J. A., Manning M. C. (2000) Long chain arginine esters: A new class of cationic detergents for preparation of hydrophobic ion-paired complexes, Biochemistry and Cell Biology, 78, 59-65 13. Ambrish K. Srivastava, Anoop K. Pandey, Shashi K. Gangwar, Neeraj Misra (2014) Structural, Vibrational and Electronic properties of cis and trans conformers of 4-hydroxy-Iproline: A density functional approach, Journal of Atomic and Molecular Sciences, 5, 279-288 14. Sieler G., Schweitzer-Stenner, R., Holtz, J. S., Pajcini, V., Asher, S. A. (1999) Different conformers and protonation states of dipeptides probed by polarized Raman, UV-resonance Raman, and FTIR spectroscopy. The Journal of Physical Chemistry B, 103(2), 372-384. 